\title{
Discuss the Properties of Structural Steel and Applications of Waste Concrete from Post-Earthquake Investigations
}

\author{
Xiaoshuang Shi ${ }^{1 *}$, Qingyuan Wang ${ }^{1}$, Yunrong Luo ${ }^{1,2}$ \\ ${ }^{1}$ College of Architecture and Environment, Sichuan University, Chengdu, China \\ ${ }^{2}$ College of Mechanical Engineering, Sichuan University of Science \& Engineering, Zigong, China \\ Email: *shixs@scu.edu.cn, wangqy@scu.edu.cn, luoyunrong2004@yahoo.com.cn \\ Received March 13, 2013; revised April 16, 2013; accepted May 9, 2013
}

Copyright (C) 2013 Xiaoshuang Shi et al. This is an open access article distributed under the Creative Commons Attribution License, which permits unrestricted use, distribution, and reproduction in any medium, provided the original work is properly cited.

\begin{abstract}
This work proposes two aspects about construction materials abased on Wenchuan post-earthquake investigations. According to different feature failure modes in various damaged structures and the cause of the damage to the effects of the loading during the ground motion, the structural failures were found related to low cycle fatigue (LCF) properties of building steel. The hitherto research development is presented briefly. The characters of cycle response of the steels are tested and discussed. During the post-earthquake reconstruction process, the disposal of huge quantities of earthquake demolition waste brought great challenges. Utilizing the waste concrete taken from earthquake-stricken area as recycled coarse aggregate (RCA) in the new concrete is conducted. Furthermore, the application perspective of RCA is discussed.
\end{abstract}

Keywords: Earthquake; Failure Modes; Low Cycle Fatigue (LCF); Recycled Coarse Aggregate (RCA)

\section{Introduction}

The earthquake happens more frequently in recent years around places in the world. The damages of buildings and infrastructures cause huge loss of lives and economy. For example, the Wenchuan earthquake happened in 2008 , which is measured at 8.0 Ms according to China Seismological Bureau, occurred on 12 May in Sichuan province of China. The total disaster zone covers an area of 440,000 square kilometers. The earthquake destroyed 5.3 million houses and damaged 21 million rooms, and left about 4.8 million people homeless. About 90,000 people were counted as dead or missing. More than $80 \%$ earthquake-related deaths were caused by the collapse of man-made structures. The building construction quality played a tremendous role in the death toll of the earthquake. The collapsed and damaged structures were estimated to produce about 300 million tons of waste concrete in this earthquake [1].

Earthquake damage depends on many parameters, including intensity, duration and frequency content of ground motion, geologic and soil condition, quality of construction, etc. Building design must ensure that the building has adequate strength, high ductility, and cyclic

*Corresponding author. load capacity in which would remain as one unit, even while subjected to very large deformation. Several factors of building construction determine the structural failure from the earthquake including, the type and age of building, foundation, materials used, seismic code used and construction quality, etc. Field investigation in Mianyang area revealed that $63 \%$ of raw-soil buildings, $36 \%$ of brick-wood structures, $25 \%$ of masonry structures, and $11 \%$ of frame structures were damaged during the earthquake (Figure 1). Obviously, the anti-earthquake ability of frame structure is the best due to its stronger materials and superior building type. The failure of the buildings charges upon the failure of inner materials. To improve the properties of construction materials, which are mainly concrete and steel, is an important way to avoid or alleviate damages caused by earthquakes.

On the other hand, facing with such large amount of wastes unprecedentedly is a tough challenge in postearthquake reconstruction, especially the waste concrete takes up about $54.4 \%$ in all the types of demolition waste produced in this earthquake [2]. In general, we used to dispose the construction waste directly in landfills. However, this would take up large useful areas and result in secondary pollution, not to mention at one place in such a short time. Hence, one can see that the earthquake 


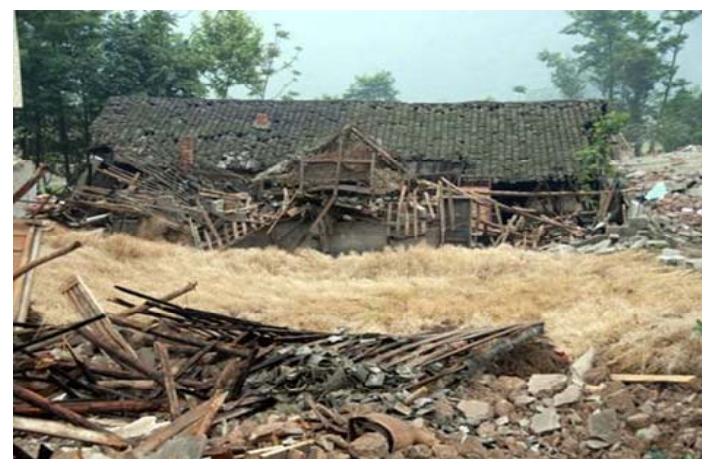

(a)

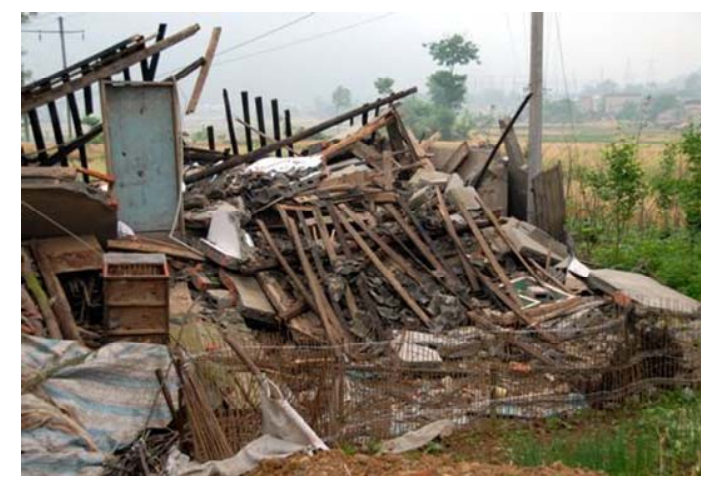

(b)

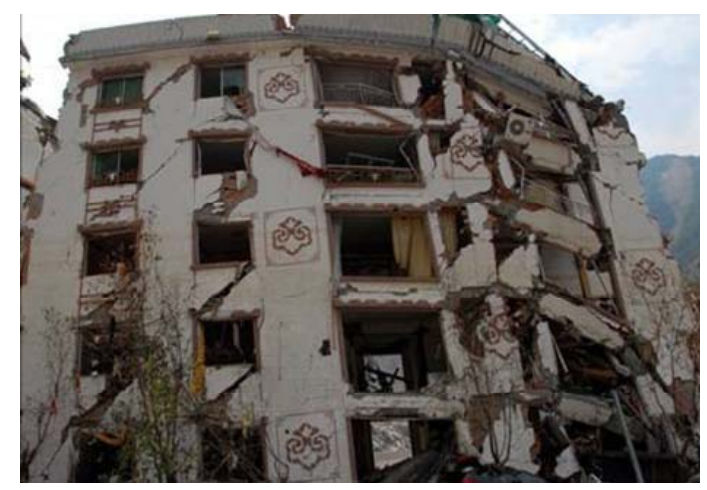

(c)

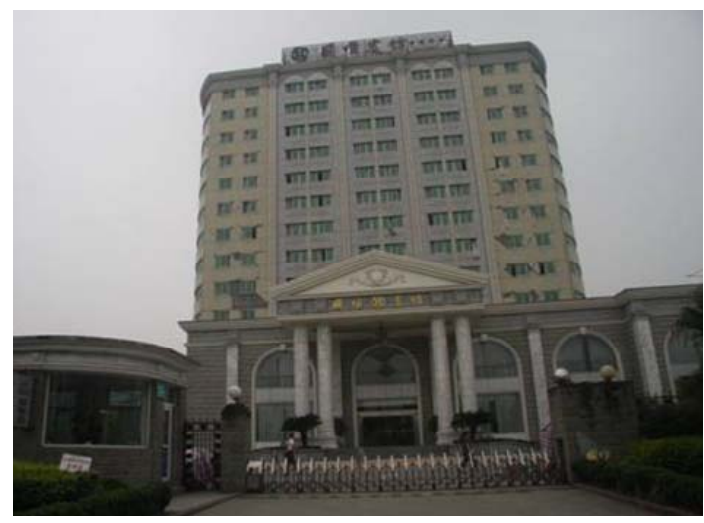

(d)

Figure 1. Earthquake damage to different buildings. (a) Raw-soil structure; (b) Brick-wood structure; (c) Masonry structure; (d) Frame structure. disaster brought us two urgent issues to think about. One is how to improve the anti-seismic ability of construction materials. The other one is how to reuse the construction waste in post-earthquake reconstruction.

\section{Low Cycle Fatigue Behavior of Structural Steel}

As rapid development of high-rise buildings, steel as an indispensable construction material is now used more widely in the construction. The principal cause of earthquake-induced failure is ground shaking. As the earth vibrates, all buildings on the ground surface will respond to that vibration or cyclic loading. The earthquake loads acting on loading bearing elements are dynamic, in the form of high strain reversals, which can be simulated as single axis low cycle fatigue. Generally speaking, the strong shock lasts within one minute with the amplitude frequency among $1 \mathrm{~Hz}$ to $3 \mathrm{~Hz}$. The damage to the buildings always happens during 100 to 200 cycles, which belongs to high strain low cycle (HSLC) fatigue problem [3]. Under the earthquake load, the HSLC property could be the control factor to the anti-seismic ability of structural steel. At present, many researches based on axial loading tests have been investigated [4-9]. The low cycle fatigue properties are studied according to Coffin-Manson empirical formula. The studies were more about ductility and energy dissipation effect of low yield steel, while the low cycle fatigue property of high-strength structural steels is barely reported.

The low cycle fatigue behavior of high-strength structural steel under asymmetrical total strain control can be investigated on cylindrical specimens with a gauge length of $20 \mathrm{~mm}$ and central diameter of $10 \mathrm{~mm}$, shown in Figure 2. The tests were carried out under uniaxial tension-compression loading with total strain control at a given strain amplitude of $0.4 \%-1.0 \%$ and a strain ratio of -1 . The triangular waveform was employed for all the fatigue tests. The total strain was measured using a dynamic extensometer with a span length of $12.5 \mathrm{~mm}$ which was attached to the specimen. The cyclic stress response curves of structural steel Q235 and Q345 under different strain amplitude are shown in Figures 3 and $\mathbf{4}$, respectively. The stress amplitude is the average value of the maximum tensile stress and compressive stress. It can be found that the feature of cyclic stress response curves is related to strain range. The materials are cyclic softening firstly when the strain amplitude is lower than $0.5 \%$. After that, Q235 exhibited cyclic hardening and Q345 displayed cyclic stability until fracture. However, when the strain amplitude was upon $0.5 \%$, both of the materials performed sharply cyclic hardening at the initial stage about $0.02 \mathrm{Nf}$, and then were followed by slightly cyclic hardening until fracture. Overall, cyclic hardening is the main character of the materials' cyclic feature, which is 


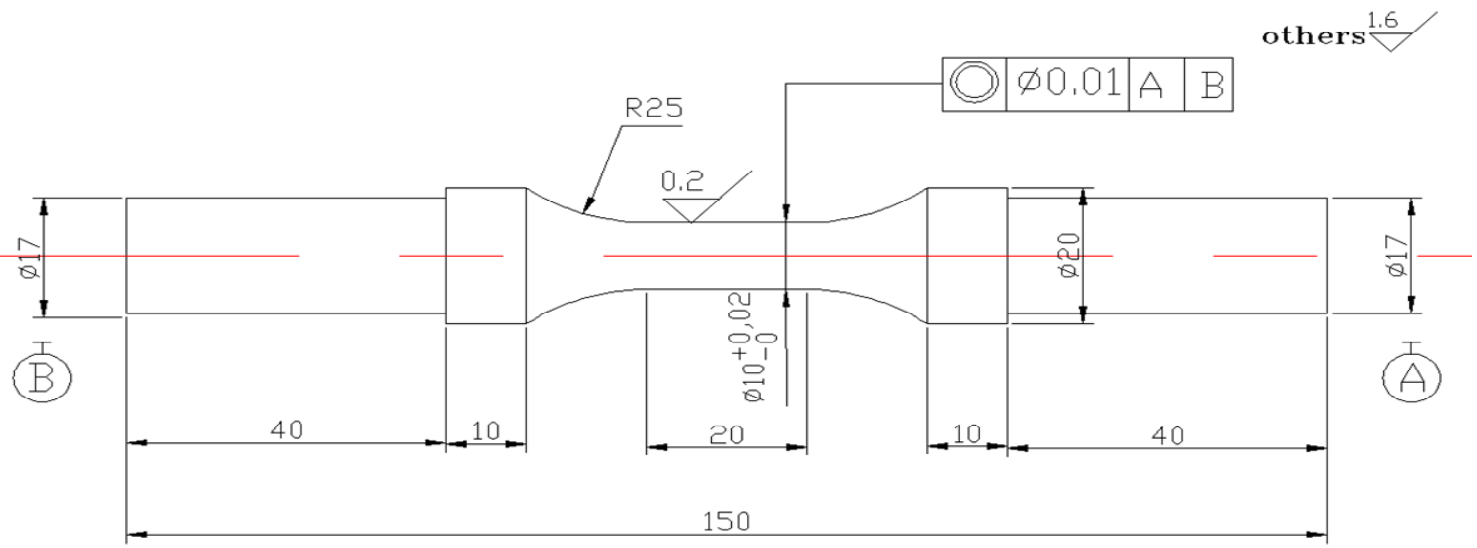

Figure 2. Geometry of specimen (Unit: $\mathbf{m m}$ ).

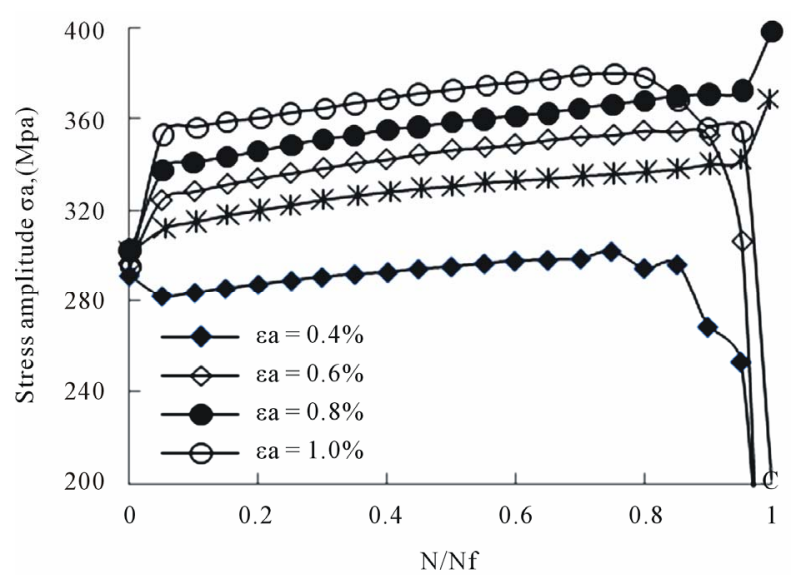

Figure 3. Cyclic stress response of Q235.

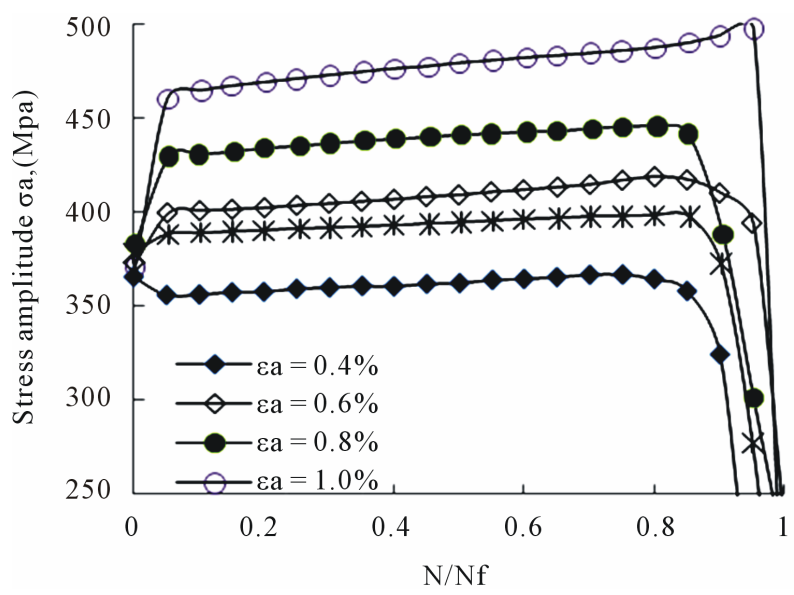

Figure 4. Cyclic stress response of Q345.

benefit for the material to avoid failure too early under large cyclic stress loading due to the decreased strength resulted from softening. Therefore, the structural steel equipped with good anti-seismic property should perform cyclic hardening or cyclic stability for the cycle response characters.

In recent years, some applications such as dampers based on the use of stiffened plates made of special low-yield strength steel has become a trend of earthquake resistant design. The buildings are protected well by the devices which absorb a lot of seismic energy. Steels with low yield point have good ductility and plasticity, with yield strength as low as $110 \mathrm{MPa}$ and elongation as high as $60 \%$.

The cyclic stress response curve of the steel (at 3\% strain amplitude) is shown in Figure 5. It can be found that the material exhibited cyclic hardening at the initial stage and kept cyclic stability until failed, which shows very good ability for energy absorbing under cyclic loading. So, this kind of structural steel shows great potential in earthquake design. The fracture surfaces of the samples are shown in Figure 6. The propagation of fatigue crack was mainly characterized by striations and dimples in Figures 6(b) and (c). Finally, the fatigue cracks propagated resulting in ductile fracture with many dimples.

\section{Using Recycled Aggregate in New Concrete}

Recycled aggregate is made by process of crushing waste concrete into the diameter smaller than $40 \mathrm{~mm}$. With the

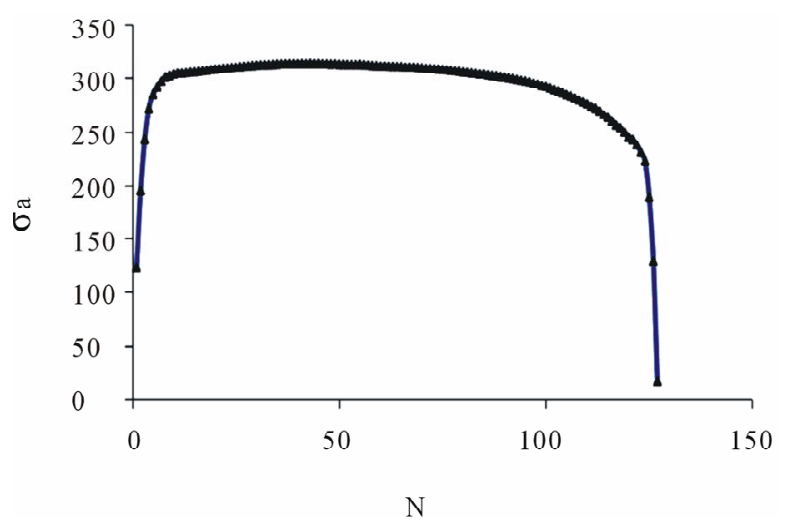

Figure 5. Cyclic stress response of special structure steel. 


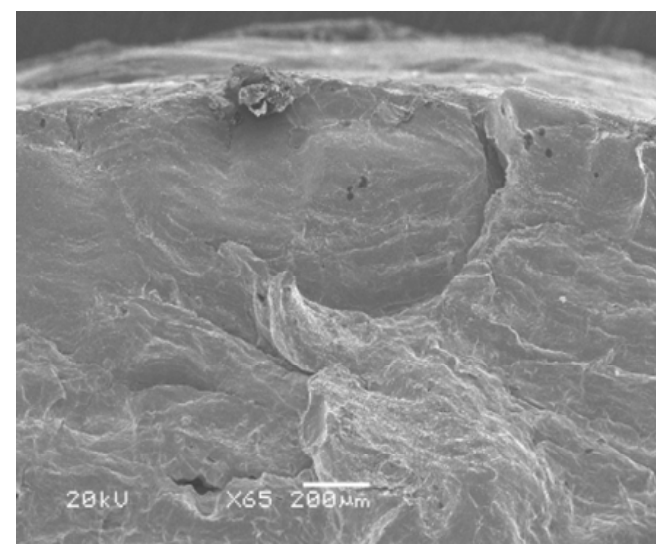

(a)

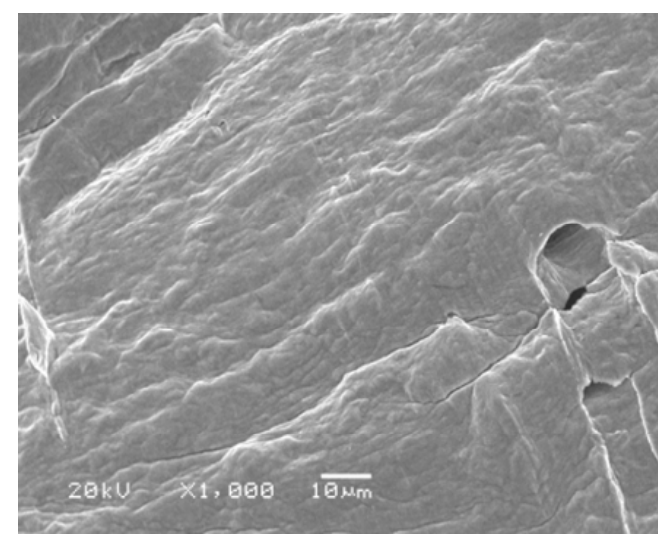

(b)

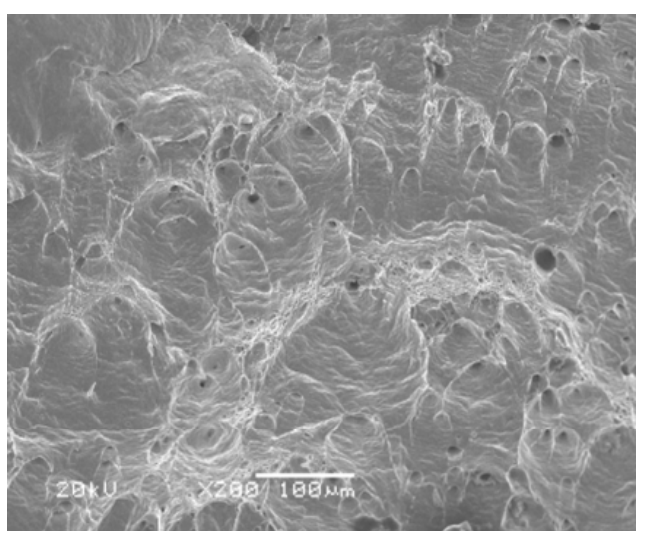

(c)

Figure 6. SEM images of fracture surfaces.

diameter among $5 \mathrm{~mm}$ to $40 \mathrm{~mm}$ belongs to recycled coarse aggregate (RCA). Using RCA substituting natural aggregate partially or totally to manufacture new concrete is recycled aggregate concrete (RAC). The research about RAC is more and more popular in recent years, especially after Wenchuan earthquake [10-16]. As the waste concrete comparatively assembled at one place, this is an economic and effective way to solve the large amount of demolition waste in the earthquake-stricken area.
The properties of aggregate made from demolition waste in earthquake-stricken area Dujiangyan were investigated [17]. The test results show that the water absorption of RCA is the most different factor from natural aggregate, which is 3.5 times higher. The density of RCA is about $10 \%$ lower than that of natural aggregate. The 28-days compressive strength of RAC with $100 \%$ RCA replacement ratio decreased $16.7 \%$ compared with ordinary concrete, which is shown in Figure 7. The research studied by Hansen [18] indicated that the strength of RAC decrease about 5\% to $32 \%$ compared with ordinary concrete. RCA contents and cement to water ratio are the key factors to influence the strength of the concrete.

Nowadays, the application of RCA in RAC has been accepted and developed into practical projects. This makes people have more confident on the utilization of RCA, so the research about novel application of RCA in various concretes has been heated up. From the sustainable development point of view, the research on RCA used in geopolymer concrete is studied. Six mixtures were made with different RCA replacement ratios $(0 \%$, $50 \%$ and $100 \%$ ) to compare the properties of RAC and geopolymeric recycled concrete (GRC). The compressive strengths of different concretes shown in Figure 8 [19] present that the influence of RCA to GRC is similar with that to RAC, and with appropriate mixture design the application of RCA in geopolymer concrete is feasible.

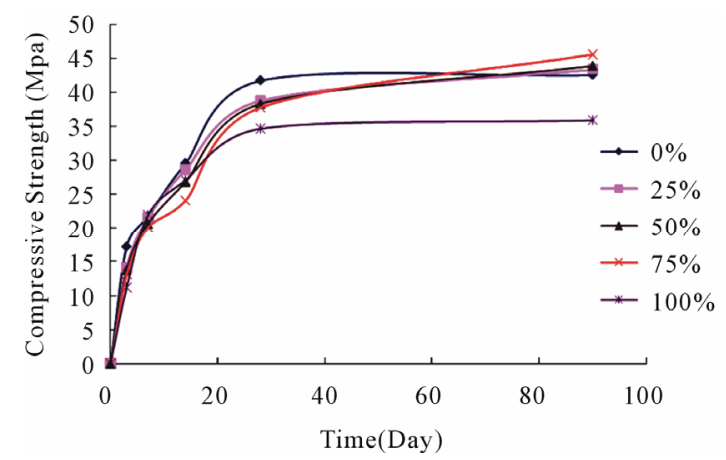

Figure 7. Compressive strength of RAC with different RA\% vs. time [17].

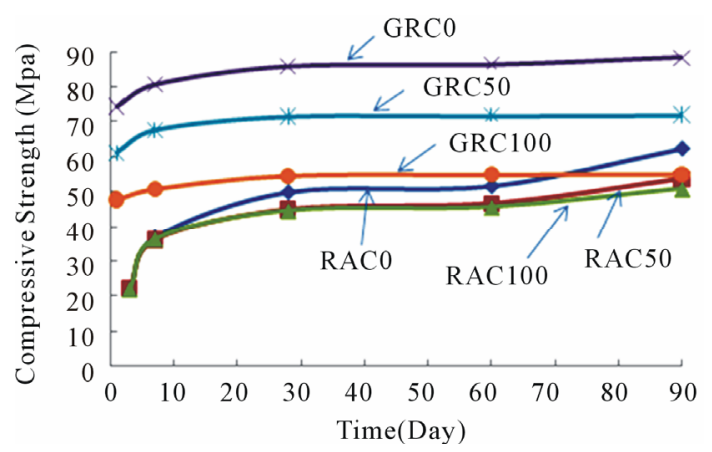

Figure 8. Compressive strength of RAC and GRC with different RA\% vs. time [19]. 
Besides the study on the concrete with RCA, the mechanical properties of recycled concrete filled steel tube (RACFST) columns were also investigated in previous study [20]. According to the experimental results, the ultimate load capacity of RACFST is lower than ordinary concrete filled with steel tube columns (CFT) within $20 \%$. The failure mode of RACFST is similar to those of conventional CFT columns with local buckling resulting in failure. The ultimate load of RACFST decreased with increasing RCA replacement ratio. Also, Yang and Han [21] reported the similar research work and results. Therefore, it could be concluded that RACFST column has slightly lower but comparable load capacity compared with conventional CFT column.

\section{Concluding Remarks}

The lessons from the deadly earthquake should be carefully studied, in order to improve the anti-seismic ability of the buildings. Overall, construction materials play a crucial role in earthquake and post-earthquake event. Structural steel as the major construction material used in the buildings is pointed out, and its LCF property is discussed in this paper which could demonstrate its antiseismic ability. It is found that the material with cyclic hardening or cyclic stability characters benefits for antiseismic ability. On the other hand, the disposal of demolition waste in earthquake-stricken area is also very important. The properties of RAC are comparable similar to ordinary concrete. Presently, the research and application about reusing waste concrete into RAC are approaching mature. However, more widely utilization of recycled aggregate in other kinds of concrete or novel materials should be explored and further studied.

\section{Acknowledgements}

Authors gratefully acknowledge the support from National Natural Science Foundation of China (NSFC 10925211 and NSFC 51208325), and Program for Changjiang Scholars and Innovative Research Team (IRT1027).

\section{REFERENCES}

[1] X. S. Shi, Q.-Y. Wang, C.-C. Qiu and X.-L. Zhao, "Recycling Construction and Demolition Waste as Sustainable Environmental Management in Post-Earthquake Reconstruction," 4th International Conference on Bioinformatics and Biomedical Engineering, Chengdu, 18-20 June, 2010, pp. 18-20.

[2] J. Z. Xiao, H. Xie and C. Q. Wang, "Statistical Analysis on Building Waste in Wenchuan Earthquake-Hit Area," Journal of Sichuan Univeristy (Engineering Science Edition), Vol. 42, No. 41, 2009, pp. 188-194.

[3] S. H. Gong and G. M. Sheng, "Effects of Toughness of Steel on Seismic Performance of Building Structures,"
Earthquake Resistant Engineering, Vol. 6, No. 3, 2004, pp. 41-47.

[4] T. Nishimura and C. Miki, "Strain Controlled Low Cycle Fatigue Behavior of Structural Steels," Proceedings of the Japan Society of Civil Engineers, Vol. 279, No. 1, 1978, pp. 29-44.

[5] K. Shimada, J. Komotori and M. Shimizu, "The Application of the Manson-Coffin Law and Miner's Law to Extremely Low Cycle Fatigue," Journal of Japan Society of Mechanical Engineers, Vol. 53, No. 491, 1987, pp. 11781185. doi:10.1299/kikaia.53.1178

[6] K. Masatoshi, "Extremely Low Cycle Fatigue Life Prediction Based on a New Cumulative Fatigue Damage Model," International Journal of Fatigue, Vol. 24, No. 6, 2001, pp. 699-703.

[7] J. B. Mander, F. D. Panthaki and A. Kasalanati, "LowCycle Fatigue Behavior of Reinforcing Steel," Journal of Materials in Civil Engineering, Vol. 6, No. 4, 1994, pp. 453-468. doi:10.1061/(ASCE)0899-1561(1994)6:4(453)

[8] W. C. Liu, Z. Liang and G. C. Lee, "Low-Cycle BendingFatigue Strength of Steel Bars under Random Excitation. Part I: Bahavior," Journal of Structural Engineering, ASCE, Vol. 131, No. 6, 2005, pp. 913-918.

[9] K. A. S. Susantha, T. Aoki and T. Kumano, "Applicability of Low Yield Strength Steel for Ductility Improvement of Steel Bridge Piers," Engineering Structures, Vol. 27, No. 7, 2005, pp. 1064-1073. doi:10.1016/j.engstruct.2005.02.005

[10] I. Gull, "Testing of Strength of Recycled Waste Concrete and Its Applicability," Journal of Construction Engineering and Management-ACSE, Vol. 137, No. 1, 2011, pp. 1-5. doi:10.1061/(ASCE)CO.1943-7862.0000255

[11] R. J. Wang and D. J. Yang, "Experimental Research on Compressive Strength and Elastic Modulus of Recycled Concrete," International Conference on Civil Engineering, Baoding, 19-20 July 2010, pp. 791-795.

[12] V. Corinaldesi, "Mechanical and Elastic Behaviour of Concretes Made of Recycled-Concrete Coarse Aggregates," Construction and Building Materials, Vol. 24, No. 9, 2010, pp. 1616-1620. doi:10.1016/i.conbuildmat.2010.02.031

[13] J. Z. Xiao, J. D. Huang and M. Wei, "Study on Application of Recycled Aggregate Concrete in Sustainable Buildings," Proceedings of International Conference of Technology of Architecture and Structure, Shanghai, 15-17 October 2009, pp. 753-764.

[14] K. H. Obla and H. Kim, "Sustainable Concrete through Reuse of Crushed Returned Concrete," Transportation Research Record, Vol. 2113, No. 14, 2009, pp. 114-121. doi:10.3141/2113-14

[15] G. Durmus, O. Simsek and M. Dayi, "The Effects of Coarse Recycled Concrete Aggregates on Concrete Properties," Journal of the Faculty of Engineering and Architecture of Gazi University, Vol. 24, No. 1, 2009, pp. 183-189.

[16] Z. L. Cui, M. Kitatsuji and R. Tanaka, "The Experimental Research on Durability of Recycled Aggregate Concrete," Proceeding of International Disaster and Risk Confer- 
ence, Chengdu, 13-15 July 2009, pp. 449-452.

[17] X. S. Shi, Q.-Y. Wang, C.-C. Qiu and X.-L. Zhao, "Experimental Study on the Properties of Recycled Aggregate Concrete with Different Replacement Ratios from Earthquake-Stricken Area," Sichuan Daxue Xuebao (Engineering Science Edition), Vol. 42, Supp. 1, 2010, pp. 170-176.

[18] T. C. Hansen, "Recycled Aggregate Concrete Sencond State-Of-Art Report Developments 1945-1985," Material and Structure, Vol. 19, No. 3, 1986, pp. 201-246. doi:10.1007/BF02472036

[19] X. S. Shi, F. G. Collins, X. L. zhao and Q. Y. Wang, "Experimental Study on Geopolymeric Recycled Concrete Using as Sustainable Construction Material," Proceeding of International Conference on Advances in Construction Materials through Science and Engineering, Hong Kong SAR, 2011, pp. 186-194.

[20] X. S. Shi, Q. Y. Wang, C. C. Qiu and X. L. Zhao, "Mechanical Properties of Recycled Concrete Filled Steel Tubes and Double Skin Tubes," 2nd International Conference on Waste Engineering Management, Shanghai, 13-15 October 2010, pp. 559-567.

[21] Y. F. Yang and L. H. Han, "Experimental Behaviour of Recycled Aggregate Concrete Filled Steel Tubular Columns," Journal of Constructional Steel Research, Vol. 62, No. 12, 2006, pp. 1310-1324. doi:10.1016/j.jcsr.2006.02.010 